\title{
Pemanfaatan Akses Jurnal Elektronik (E-Journal) Dengan Media Smartphone (Studi Kasus Mahasiswa Program Studi Ilmu Perpustakaan Angkatan 2016-2017 Fakultas Adab Dan Humaniora UIN Raden Fatah Palembang)
}

\author{
Riski Andini ${ }^{1 *}$ \\ ${ }^{1}$ Fakultas Adab dan Humaniora UIN Raden Fatah Palembang \\ *Korespondensi: riskiandini733@gmail.com
}

\begin{abstract}
This study discusses "Utilization of Electronic Journal Access (E-Journal) with Smartphone Media (Case Study of 2016-2017 Students of Library Science Study Program Faculty of Adab and Humanities of Uin Raden Fatah Palembang)". This research is a quantitative descriptive research. Data collection is done by observation, questionnaires and documentation. The sample in this study was 62 respondents with a simple random sampling technique. The results showed that the smartphone utilization variable with a value of 3.52 between the intervals of 3.43 - 4.23 was considered high. Furthermore, the results showed the variable utilization of access to electronic journals (e-journals) by students of the 2016-2017 Library Science Study Program with a value of 3.67 among the intakes of 3.43 - 4.23 in the high category. And the results of the influence of smartphones on the use of access to electronic journals (e-journals) by the Library of Science Study Program Students Force 2016 2017 Faculty of Adab and Humanities there is an influence of 60.9\% with the criteria of Ho being rejected and Ha accepted stating that the influence of smartphones on utilization access to electronic journals (e-journals) by the 2016-2017 Library Science Study Program Students of the Adab and Humanities Faculty.
\end{abstract}

Keywords: smartphone; Utilization (e-journal); electronic journal

\begin{abstract}
Abstrak
Pemanfaatan Akses Jurnal Elektronik (E-Journal) dengan Media Smartphone (Studi Kasus Mahasiswa Program Studi Ilmu Perpustakaan Angkatan 2016-2017 Fakultas Adab dan Humaniora UIN Raden Fatah Palembang)". Penelitian ini merupakan penelitain deskriptif kuantitatif. Pengumpulan data dilakukan dengan observasi, kuesioner dan dokumentasi. Sampel dalam penelitian sebanyak 164 responden dengan teknik sampling jenuh. Hasil penelitian menunjukkan variabel pemanfaatan smartphone dengan nilai 3,65 di antara interval 3,42-4,23 dikategorikan tinggi. Selanjutnya hasil penelitian menunjukan variabel pemanfaatan akses jurnal elektronik $(e-$ journal) oleh mahasiswa prodi Ilmu Perpustakaan Angkatan 2016-2017 dengan nilai 3,76 di antara inteval 3,424,23 dikategorikan tinggi. Hasil pengaruh smartphoneterhadappemanfaatanakses jurnal elektronik (e-journal) oleh Mahasiswa Program Studi Ilmu Perpustakaan Angkatan2016-2017 Fakultas Adab dan Humaniora adanya pengaruh sebesar 31,8\% dengan kreteria Ho di tolak dan Ha diterima menyatakan bahwa adanya pengaruh smartphone terhadap pemanfaatan akses jurnal elektronik (e-journal) oleh Mahasiswa Program Studi Ilmu Perpustakaan Angkatan 2016-2017 Fakultas Adab dan Humaniora.
\end{abstract}

Kata Kunci: Smartphone; Pemanfaatan (e-journal); Jurnal elektronik

\section{PENDAHULUAN}

Di era modern saat ini pengguna internet sangat meningkat atau telah menyebar hampir di semua bidang tidak terkecuali dalam bidang penerbitan, pemberitaan dan perpustakaan. Hal ini memberikan manfaat besar bagi perkembangan dunia jurnalistik sampai pada munculnya media online (internet) yang di dalamnya memuat tulisan baik itu dalam bentuk artikel, berita, tulisan ilmiah maupun buku dalam format elekronik. Menjadikan informasi dan berita menjadi lebih cepat sampai dan penyebarannya sangat luas dan up to date. Keberadaan teknologi ini menjadikan infomasi menjadi sangat mudah tersebar dan sangat luas jangkauannya. Tidak terkecuali dengan perkembangnya penyebaran informasi karya ilmiah yang dapat diakses secara online seperi $e$ jurnal yang diterbitkan oleh berbagai macam instansi jurnal. Perkembangan ini terus terjadi dengan kemudahan saat ini, pencari informasi tidak susah untuk mencari sebuah informasi terpercaya karena dengan Smartphone yang saat ini telah menjadi barang yang sangat penting bagi manusia sebab dengan smartphone apapun bisa dilakukan, di mana pun dan kapan pun. 
Riski Andini/ Pemanfaatan Akses Jurnal Elektronik (E-Journal) dengan Media Smartphone (Studi Kasus Mahasiswa Program Studi Ilmu Perpustakaan Angkatan 2016-2017 Fakultas Adab dan Humaniora UIN Raden

Fatah Palembang)

Smartphone adalah telepon genggam yang mempunyai kemampuan dengan pengunaan dan fungsi yang menyerupai komputer. Belum ada standar pabrik yang menentukan arti ponsel pintar (Petersalim \& Yennisalim, 1999). Smartphone dalam kamus Oxford, diartikan sebagai telepon pintar yang memiliki kemampuan seperti komputer, biasanya memiliki layar yang besar dan sistem operasinya mampu menjalankan tujuan aplikasi-aplikasi yang umum (Oxford, t.t.).

Smartphone yang pada umumnya di ciptakan sebagai sarana alat komunikasi jarak jauh, mendengarkan musik, mengambil foto, bermain game, dam berselancar di dunia maya. Tetapi di samping itu pula pada zaman millenial saat ini yang kemudahan dan kemajuan teknologi serta kebutuhann informasi yang semakin meningkat smartphone juga beralih fungsi sebagai salah satu media elektronik yang dapat mendukung dalam hal pendidikan melalui fitur internet yang dapat memberikan kemudahan bagi penggunanya dalam mencari sebuah informasi (Nikmah, 2016).

Pemanfaatan smartphone dimaksudkan untuk kebutuhan mencari dan mendapatkan informasi secara efektif dan efesien di mana saja dan kapan saja selama 24 jam. Berbagai informasi tersebut tersedia di dalam aplikasi pada smartphone yang dapat diakses secara mudah. Penggunaan smartphone tidak dibatasi oleh waktu dan tempat. Proses mendapatkan informasi dengan menggunakan smartphone juga lebih mutakhir seiring dengan pertumbuhan informasi dari waktu ke waktu. Kemudahan inilah yang membuat smartphone sangat digemari saat ini.

Jurnal merupakan bagian penting dari koleksi perpustakaan yang menjadi kendaraan yang paling penting untuk komunikasi ilmiah global. Perkembangan luar biasa dalam beberapa tahun terakhir telah memberikan dorongan luar biasa untuk penerbitan elektronik. Akibatnya informasi yang sedang dihasilkan pada dengan modem dan perangkat lunak yang sesuai dapat memproduksi dan mendistribusikan e-journal melalui jaringan komputer, sehingga penerbitan jurnal sedang menglobalisasi. Biasanya, e-jurnal yang diterbitkan sama atau setara dengan jurnal tercetak seperti biasa tetapi akhir-akhir ini ada peningkatan jumlah jurnal ilmiah yang diterbitkan hanya secara elektronik. Akibatnya, e-jurnal telah muncul sebagai komponen penting dari sumber daya informasi dari perpustakaan dan memainkan peran penting kecepatan intens dari seluruh dunia melalui web untuk semua tema sekarang sedang diterbitkan dalam bentuk jurnal elektronik ( $e$ jurnal) dalam distribusi informasi utama. E-jurnal yang pun dengan akses ke komputer yang dilengkapi telah ditentukan dengan cara yang berbeda oleh penulis yang berbeda.

Salah satu koleksi digital yang dimiliki perpustakaan adalah database online yang berupa buku elektronik dan jurnal elektronik. Jurnal elektronik merupakan perubahan dari jurnal tercetak yang dapat dijadikan sebagai referensi ilmiah. Hingga awal 1990-an, jurnal ilmiah tercetak merupakan fokus kegiatan ilmiah yang menjadi koleksi utama pada perpustakaan perguruan tinggi (Indonesia, 2007). Penggunaan jurnal elektronik semakin banyak daripada jurnal tercetak karena memiliki banyak keunggulan. Jurnal elektronik atau e-journal yang sering kali sudah terbit dahulu sebelum jurnal tercetak (Rejeki, 2013). Pemanfaatan jurnal elektronik juga bisa menghemat waktu, biaya, dan tenaga. Mahasiswa dapat memanfaatkan jurnal elektronik tersebut di mana saja dan kapan saja. Pustakawan juga tidak perlu mengindeks jurnal tersebut. Fungsi utama jurnal tetap sama yaitu mendaftar, menyebarkan, memeriksa, dan melestarikan ilmu pengetahuan. Kehadiran jurnal elektronik diharapkan mampu menunjang penelitian serta proses pembelajaran civitas akademika perguruan tinggi sebagai referensi yang dapat diakses secara mudah dan cepat.

Perpustakaan Perguruan Tinggi Islam Negeri Raden Fatah Palembang dalam menunjang terselenggaranya Tri Dharma Perguruan Tinggi, menghimpun dan mengolah serta menyebarluaskan informasi bidang ilmu pengetahuan dan teknologi serta mendokumentasikan karya ilmiah staf UIN Raden Fatah, skripsi, tesis dan disertasi lulusan UIN Raden Fatah Palembang yang dikelola berbentuk bahan pustaka tercetak dan elektronik serta Perpustakaan UIN Raden Fatah Palembang menyediakan berbagai macam Jurnal Elektronik yang dapat diakses 
secara bebas oleh mahasiswa yaitu EBSCHO, Emerald, Moraref, Ta'dib, Yonetim, Nurani, Tamddun, Intizar, El-Kiras, Tadwin, Muaddib serta jurnal elektronik lainnya. Dengan adanya jurnal elektronik tersebut, sangat membantu para civitas akademika untuk mendukung proses pembelajaran termasuk juga referensi untuk penulisan skripsi dan penelitian ilmiah.

Berdasarkan hal tersebut dan semakin majunya zaman serta kebutuhan informasi pengguna yang beragam dan kemudahan yang diinginkan maka saat ini sebagai seorang Mahasiswa yang dapat mengikuti perkembang zaman millennial, serta sebagai kesadaran diri bahwa teknologi informasi yang berkembang saat ini (Smartphone) bukan hanya dapat digunakan sebagai alat komunikasi, media sosial dan kemudahan lainnya tetapi Smartphone juga dapat sebagai media penyimpanan, pencarian, dana alat untuk menemukan informasi elektornik seperti jurnal-jurnal elektronik yang sekarang dapat digunakan dan diakses di mana pun.

\section{METODE PENELITIAN}

Jenis penelitian yang digunakan adalah penelitian kausalitas dengan pendekatan kuantitatif. Penelitian kausalitas adalah hubungan sebab akibat atau bila X maka Y (Sugiyono, 2007). Biasanya dilakukan untuk mengkaji kemungkinan hubungan sebab akibat antara faktor tertentu yang mungkin menjadi penyebab gejala yang diselidiki (Zuriyah, 2009). Metode penelitian kuantitatif adalah penelitian yang berlandaskan pada filsafat positivisme, digunakan untuk meneliti pada populasi atau sampel tertentu, pengumpulan data menggunakan instrumen penelitian, analisis data yang bersifat kuantitatif/statistik, dengan tujuan untuk menguji hipotesis yang telah ditetapkan (Sugiyono, 2015). Sumber data dalam penelitian kuantitatif berisi uraian apa saja dikumpulkan untuk penelitian dan siapa saja yang menjadi informasi untuk mendapatkan data yang diperlukan.

Dalam penelitian ini penulis menggunakan sumber data primer dan sumber data sekunder.

a. Sumber data primer, yaitu data yang diperoleh secara langsung dari responden dari tempat penelitian. Dalam penelitian ini, sumber data yang diperoleh dari tempat penelitian berupa kata-kata dan tindakan yang diperoleh melalui observasi dan wawancara terhadap responden, atau sumber data yang dikumpulkan langsung dari para mahasiswa Program Studi Ilmu Perpustakaan Universitas Islam Negeri Raden Fatah Palembang, Tahun Angkatan 2016-2017.

b. Sumber data sekunder, yaitu penunjang yang dapat mendukung data primer. Data sekunder dalam penelitian ini bersumber dari dokumen yang dapat menunjang penelitiannya berupa literatur yang berkaitan dengan penelitian ini. Data sekunder bersumber dari kepustakaan, yang terdiri dari berbagai literatur dari bahan tertulis berupa buku, jurnal dan dokumen yang berkaitan.

\section{HASIL DAN PEMBAHASAN}

Hasil penelitian penulis yang berjudul Pemanfaatan Akses Jurnal Elektronik (E-Journal) dengan Media Smartphone (Studi Kasus Mahasiswa Program Studi Ilmu Perpustakaan Angkatan 2016-2017 Fakultas Adab dan Humaniora). Data yang penulis peroleh berdasarkan hasil observasi, wawancara, dan penyebaran angket.

Angket dalam penelitian ini penulis bagikan kepada mahasiswa prodi Ilmu Perpustakaan Angkatan 2016-2017, dengan total 164 orang. teknik pengambilan sampel menggunakan sampling jenuh sehingga sampel diambil keseluruhan sama dengan populasi sehingga menghasilkan 164 responden sebagai sampel penelitian.

Pengambilan data dilakukan dengan cara menyebarkan angket yang telah dibuat dengan 20 pernyataan yang berhubungan dengan pemanfaatan akses jurnal elektronik ( $e$-journal) dengan media Smartphone berdasarkan teori Handoko dan Hidayat, yang mana untuk Teori Handoko 
Riski Andini/ Pemanfaatan Akses Jurnal Elektronik (E-Journal) dengan Media Smartphone (Studi Kasus Mahasiswa Program Studi Ilmu Perpustakaan Angkatan 2016-2017 Fakultas Adab dan Humaniora UIN Raden

Fatah Palembang)

dijadikan sebagai acuan dari variabel Y yakni Jurnal Elektronik (e-Journal) dan Teori Handoko dijadikan sebagai acuan dari variabel X yakni smartphone. Selanjutnya Skala Likert digunakan sebagai acuan untuk menghasilkan data kuantitatif. Berikut Skala Likert yang digunakan:

Tabel 1

Pengukuran Skala Likert

\begin{tabular}{|c|c|c|c|}
\hline No & Skala Likert & Pernyataan & Nilai \\
\hline 1 & SL & Selalu & 5 \\
\hline 2 & S & Sering & 4 \\
\hline 3 & KD & Kadang-kadang & 3 \\
\hline 4 & JR & Jarang & 2 \\
\hline 5 & TP & Tidak Pernah & 1 \\
\hline
\end{tabular}

Sumber: Sugiono, Metode Penelitian Pendidikan

Skala yang digunakan merupakan skala ordinal, memberikan informasi tentang jumlah relatif karakteristik yang berbeda yang dimiliki oleh objek atau individu tertentu (Wijaya, 2011). Agar analisa ini menjadi lebih luas, maka skala ordinal dapat diubah menjadi skala interval yaitu dimana objek atau kategori dapat diurutkan berdasarkan atribut yang memberikan informasi tentang interval antara tiap objek kategori sama. Besarnya interval dapat ditambah atau dikurangi. Cara tersebut dapat dirumuskan dengan rumus sebagai berikut (Hasan, 2002):

Skala interval $=\{a(m-n): b\}$

Keterangan :

$\mathrm{a}=$ jumlah atribut

$\mathrm{m}=$ skor tertinggi

$\mathrm{n}=$ skor terendah

$\mathrm{b}=$ jumlah skala penilaian yang ingin dibentuk

Jika skala penilaian yang ingin dibentuk berjumlah 5, dimana skor terendah adalah 1 dan skor tertinggi adalah 5, maka skala interval skor pemanfaatan dapat dihitung seperti : $\{1(5-1): 5\}=$ 0,8 . Jadi jarak setiap titik adalah 0,8 sehingga diperoleh kriteria penilaian sebagai berikut:

Tabel 2

Kriteria Penilaian

\begin{tabular}{|c|c|}
\hline \multicolumn{2}{|c|}{ Kriteria Penilaian } \\
\hline Sangat Tinggi & $4,24-5,04$ \\
\hline Tinggi & $3,43-4,23$ \\
\hline Sedang & $2,62-3,42$ \\
\hline Rendah & $1,81-2,61$ \\
\hline Sangat Rendah & $1,00-1,80$ \\
\hline
\end{tabular}

Sumber: perhitungan skala interval

1. Analisis Indikator Pemanfaatan Smartphone Guna Akses Jurnal Elektronik (E-Journal) oleh Mahasiswa Program Studi Ilmu Perpustakaan Angkatan 2016-2017 Fakultas Adab dan Humaniora UIN Raden Fatah Palembang

Untuk mengukur smartphone, penulis menggunakan teori Hidayat yang telah di jelaskan pada bab sebelumnya indikator smartphone yang dikembangkan oleh Hidayat menyatakan ada tiga hal yang diperhatikan dalam memanfaatkan smartphone yaitu frekuensi penggunaan, tujuan pengguna, kemampuan pengguna dalam menelusur koleksi (informasi). Selanjutnya penulis membuat penjelasan dari indikator tersebut menjadi pernyataan yang relevan dengan teori tersebut.

Berdasarkan perhitungan presentase, peneliti membuat rekapitulasi dari 10 pernyataan dalam tabel di bawah ini sebagai berikut: 
Tabel 3

Rekapitulasi Pernyataan

\begin{tabular}{|c|c|c|c|}
\hline No & Indikator & Nilai & Kategori \\
\hline 1 & $\begin{array}{l}\text { Saya mengakses e-jurnal dengan } \\
\text { menggunakan Smartphone. }\end{array}$ & 3,59 & Tinggi \\
\hline 2 & $\begin{array}{l}\text { Saya mengakses e-jurnal dengan smartphone } \\
\text { hanya untuk mengisi waktu luang saja. }\end{array}$ & 4,04 & Tinggi \\
\hline 3 & $\begin{array}{l}\text { Saya lebih sering mengakses e-jurnal dengan } \\
\text { smartphone dibandingkan dengan komputer. }\end{array}$ & 3,84 & Tinggi \\
\hline 4 & $\begin{array}{l}\text { Saya mengakses e-jurnal dengan smartphone } \\
\text { hanya membaca saja tanpa mengunduhnya. }\end{array}$ & 3,41 & Sedang \\
\hline 5 & $\begin{array}{l}\text { Saya mengakses e-jurnal dengan smartphone } \\
\text { dengan cara membaca dan mengunduhnya. }\end{array}$ & 3,71 & Tinggi \\
\hline 6 & $\begin{array}{l}\text { Saya mengakses e-jurnal dengan media } \\
\text { smartphone minimal } 2 \text { kali dalam seminggu. }\end{array}$ & 3,93 & Tinggi \\
\hline 7 & $\begin{array}{l}\text { Saya masih belum banyak mengetahui cara } \\
\text { mengakses } e \text {-jurnal melalui smartphone. }\end{array}$ & 3,35 & Sedang \\
\hline 8 & $\begin{array}{l}\text { Saya sudah cukup lancar dalam memanfaatkan } \\
\text { smartphone untuk mengakses } e \text {-jurnal. }\end{array}$ & 3,73 & Tinggi \\
\hline 9 & $\begin{array}{lccc}\text { Sering terjadinya gangguan saat } & \text { saya } \\
\text { mengakses } e \text {-jurnal dengan smartphone. } & \end{array}$ & 3,71 & Tinggi \\
\hline 10 & $\begin{array}{l}\text { Minimnya daya simpan pada smartphone } \\
\text { sehingga saya tidak mengunduh e-jurnal yang } \\
\text { diakses. }\end{array}$ & 3,23 & Sedang \\
\hline & Jumlah & \multicolumn{2}{|l|}{3,65} \\
\hline
\end{tabular}

Berdasarkan tabel diketahui rata-rata setiap indikator pernyataan di atas, maka selanjutnya akan menghitung nilai rata-rata indikator variabel $(\mathrm{X})$ "Smartphone" dengan menggunakan rumus rata-rata berikut ini:

$$
\mathrm{X}=\frac{(S 1 x F 1) \ldots \ldots \ldots+(\operatorname{Sn} x F n)}{N}
$$

Adapun berkenaan dengan teori Hidayat akan hal-hal yang mempengaruhi pemanfaatan koleksi perpustakaan yang mana pada penelitian ini adalah bahan koleksi yang berupa jurnal elektronik dan yang di pengaruhi oleh smartphone yang berdasarkan tiga indikator yang ada yakni frekuensi penggunaan, tujuan pengguna, dan kemampuan penelusuran pengguna.

Dengan demikian, berkenaan dengan hasil perolehan nilai total rata-rata indikator variabel (x) smartphone sebesar $\mathbf{3 , 6 5}$ maka penulis dapat menyimpulkan bahwa smartphone yang dimanfaatkan mahasiswa prodi Ilmu Perpustakaan guna akses jurnal elektronik dapat dikategorikan Tinggi karena berada pada interval di antara 3,43-4,23.

\section{Analisis Indikator Pemanfaatan Jurnal Elektronik (e-journal) oleh Mahasiswa Progran Studi Ilmu Perpustakaan Angkatan 2016-2017 Fakultas Adab dan Humaniora UIN Raden Fatah Palembang}

Untuk mengukur pemanfaatan jurnal elektronik (e-jurnal), penulis menggunakan teori Handoko yang telah dijelaskan pada bab sebelumnya indikator pemanfaatan dengan dua faktor yang di bagi atas : faktor internal yang meliputi (kebutuhan, motif, dan minat) sedangkan faktor eksternal yang meliputi ( kelengkepan koleksi, keterampilan pustakawan dalam melayani pengguna dan keterbatasan fasilitas dalam pencarian informasi). Selanjutnya penulis membuat penjelasan dari indikator tersebut menjadi pernyataan yang relevan dengan teori tesebut. 
Riski Andini/ Pemanfaatan Akses Jurnal Elektronik (E-Journal) dengan Media Smartphone (Studi Kasus Mahasiswa Program Studi Ilmu Perpustakaan Angkatan 2016-2017 Fakultas Adab dan Humaniora UIN Raden

Fatah Palembang)

Berdasarkan perhitungan presentase, penulis membuat rekapitulasi dari 9 pernyataan dalam tabel di bawah ini sebagai berikut:

Tabel 4

Rekapitulasi Pernyataan

\begin{tabular}{|c|c|c|c|}
\hline No & Indikator & Nilai & Kategori \\
\hline 1 & $\begin{array}{l}\text { Saya memanfaatkan e-jurnal untuk memenuhi } \\
\text { kebutuhan informasi sehari-hari. }\end{array}$ & 4,02 & Tinggi \\
\hline 2 & $\begin{array}{l}\text { Saya mengakses } e \text {-jurnal hanya untuk membantu } \\
\text { dalam tugas perkuliahan. }\end{array}$ & 4,12 & Tinggi \\
\hline 3 & $\begin{array}{l}\text { Saya lebih sering memanfaatkan koleksi e-jurnal } \\
\text { dibanding koleksi tercetak. }\end{array}$ & 3,95 & Tinggi \\
\hline 4 & $\begin{array}{lcc}\text { Saya memanfaatkan } \quad e \text {-jurnal untuk } \\
\text { mendapatkan informasi terbaru/mutakhir. }\end{array}$ & 3,62 & Tinggi \\
\hline 5 & $\begin{array}{l}\text { Koleksi e-jurnal adalah koleksi lengkap, } \\
\text { sehingga saya lebih sering memanfaatkannya. }\end{array}$ & 3,87 & Tinggi \\
\hline 6 & $\begin{array}{l}\text { Koleksi e-jurnal rata-rata menggunakan bahasa } \\
\text { asing yang membuat saya sulit untuk memahami. }\end{array}$ & 3,88 & Tinggi \\
\hline 7 & $\begin{array}{l}\text { Koleksi e-jurnal yang ada kurang sesuai dengan } \\
\text { informasi yang saya butuhkan. }\end{array}$ & 3,29 & Sedang \\
\hline 8 & $\begin{array}{l}\text { Koleksi e-jurnal hanya bisa saya akses ketika } \\
\text { berada dikampus saja. }\end{array}$ & 3,61 & Tinggi \\
\hline 9 & $\begin{array}{l}\text { Tidak tersedianya petunjuk penggunaan akses } e \text { - } \\
\text { jurnal sehingga terkadang saya merasa kesulitan } \\
\text { dalam mengaksesnya. }\end{array}$ & 3,55 & Tinggi \\
\hline & Jumlah & \multicolumn{2}{|l|}{3,76} \\
\hline
\end{tabular}

Berdasarkan tabel diketahui rata-rata setiap indikator pernyataan di atas, maka selanjutnya akan menghitung nilai rata-rata indikator variabel (Y) "Pemanfaatan Jurnal Elektronik (e-jurnal)" dengan menggunakan rumus rata-rata berikut ini:

$$
\mathrm{X}=\frac{(S 1 x F 1) \ldots \ldots \ldots+(\operatorname{Sn} x F n)}{N}
$$

Manfaat dalam Kamus Besar Bahasa Indonesia adalah sebuah kata yang memiliki arti proses atau cara untuk memanfaatkan suatu hal yang digunakan sebagaimana mestinya agar membantu dalam melakukan perbuatan tertentu. Adapun teori yang digunakan ialah teori dari Handoko, dari segi pengguna pemanfaatan bahan pustaka yakni jurnal elektronik dengan indikator kebutuhan, minat, motif, kelengkapan koleksi, dan keterbatasan fasilitas.

Dengan demikian, berkenaan dengan hasil perolehan nilai total rata-rata indikator variabel (y) pemanfaatan jurnal elektronik (e-jurnal) sebesar 3,76 maka penulis dapat menyimpulkan bahwa pemanfaatan jurnal elektronik (e-jurnal) oleh mahasiswa prodi Ilmu Perpustakaan dapat dikategorikan Tinggi karena berada pada interval di antara 3,43-4,23.

\section{Analisa Data Pengaruh Smartphone Terhadap Pemanfaatan Akses Jurnal Elektronik} (E-Journal) oleh Mahasiswa Program Studi Ilmu Perpustakaan Angkatan 2016-2017 Fakultas Adab dan Humaniora UIN Raden Fatah Palembang

\section{a. Analisa data dan pengujian hipotesis}

Dalam menganalisis pemanfaatan akses jurnal elektronik dengan media smartphone dianalisis berdasarkan standardized coefficient hasil regresi dan uji t antara pengaruh smartphone terhadap pemanfaatan akses e-jurnal. Pada suatu tingkat tertentu uji $\mathrm{t}$ dilakukan dengan melihat thitung terhadap tabel sebagaimana kriteria uji Ho diterima dan 
Ha ditolak apabila thitung $<$ tabel. Berarti tidak ada pengaruh antara variabel bebas dan variabel terikat, hasil analisis regresi dan uji t dapat dilihat pada tabel berikut ini:

Tabel 5

Hasil analisis regresi dan uji $\mathrm{t}$

Coefficients $^{\mathrm{a}}$

\begin{tabular}{|l|r|r|r|r|r|}
\hline \multirow{2}{*}{ Model } & \multicolumn{2}{|c|}{ Unstandardized Coefficients } & \multicolumn{1}{c|}{$\begin{array}{c}\text { Standardized } \\
\text { Coefficients }\end{array}$} & & \\
\cline { 2 - 4 } & \multicolumn{1}{|c|}{$\mathrm{B}$} & Std. Error & Beta & \multicolumn{1}{c|}{$\mathrm{T}$} & \multicolumn{1}{c|}{ Sig. } \\
\hline (Constant) & 17.303 & 2.235 & & 7.742 & .000 \\
Smartphone & .602 & .069 & .564 & 8.693 & .000 \\
\hline
\end{tabular}

Dengan demikian keputusan Ho ditolak dan Ha diterima apabila thitung $>t_{\text {tabel }}$ pada alpha $5 \%$. Sehingga hasil uji empiris pengaruh antara smartphone terhadap pemanfaatan akses jurnal elektronik berdasarkan tabel coefficient di atas, di peroleh thitung sebesar 8,693 $>$ dari tabel pada alpha $5 \%$ sebesar 1,996 jadi dapat disimpulkan bahwa thitung lebih besar dari tabel. Hal ini menunjukkan bahwa diterimanya Ha yang menyatakan adanya pengaruh positif dan signifikan antara smartphone terhadap pemanfaatan akses $e$-jurnal.

Dari hasil hipotesis, coefficient dapat diketahui hasil analisis regresi linier sederhana di peroleh coefficient dan untuk tabel smartphone 0,602 dengan konstanta 17,303 sehingga model persamaan regresi linier sederhana yaitu :

$$
\mathbf{Y}=\mathbf{1 7 , 3 0 3}+\mathbf{0 , 6 0 2 X}
$$

Berdasarkan hasil regresi linier di atas di interprestasikan bahwa setiap kenaikan variabel X (smartphone) 1\% maka variabel Y (Pemanfaatan akses e-jurnal) diperkirakan akan mengalami kenaikan sebesar 0,602. Dengan demikian berarti setiap pemanfaatan smartphone oleh mahasiswa/i sebesar $1 \%$ maka pemanfaatan akses e-jurnal akan mengalami peningkatan $0,602 \%$.

Berdasarkan analisa data regresi linier sederhana dapat diperoleh kesimpulan bahwa variabel bebas (smartphone) memiliki pengaruh positif terhadap variabel terikat (pemanfaatan akses e-jurnal). Dengan kata lain dapat dijelaskan bahwa apabila terjadi peningkatan pada pemanfaatan smartphone maka pemanfaatan akses e-jurnal akan mengalami peningkatan dan dari koefisien regresi linier pada variabel $\mathrm{X}$ atau variabel bebas dalam hal ini pemanfaatan akses e-jurnal mempunyai nilai 0,602.

\section{b. Uji Koefisien Determinasi}

Tabel 6

Koefisien Determinasi

Model Summary

\begin{tabular}{|l|r|r|r|c|}
\hline Model & $\mathrm{R}$ & R Square & \multicolumn{1}{|c|}{$\begin{array}{c}\text { Adjusted R } \\
\text { Square }\end{array}$} & $\begin{array}{c}\text { Std. Error of the } \\
\text { Estimate }\end{array}$ \\
\hline 1 & $.564^{\mathrm{a}}$ & .318 & .314 & 3.88214 \\
\hline
\end{tabular}

a. Predictors: (Constant), smartphone

Dari tabel model summary di atas menjelaskan bahwa nilai $\mathrm{r}$ square adalah 0,318. Jadi, sumbangan pengaruh dari variabel indenpenden (pemanfaatan akses $e$-jurnal) yaitu sebesar $(0,318$ x $100=31,8 \%)$ sedangkan sisanya $(100-31,8=68,2 \%)$ dipengaruhi oleh faktor lain yang tidak diteliti.

c. Uji Normalitas 
Riski Andini/ Pemanfaatan Akses Jurnal Elektronik (E-Journal) dengan Media Smartphone (Studi Kasus Mahasiswa Program Studi Ilmu Perpustakaan Angkatan 2016-2017 Fakultas Adab dan Humaniora UIN Raden

Fatah Palembang)

Pengujian normalitas terhadap residul regresi, pengujian dilakukan dengan menggunakan normal probability plot. Data yang normal adalah data yang membentuk titik menyebar tidak jauh dari garis diagonal. Hasil regresi linier dengan grafik normal probability plot terhadap residual eror model regresi di peroleh sudah menunjukkan adanya pola grafik yang normal yaitu adanya sebaran fisik titik-titik yang berada tidak jauh dari garis diagonal.

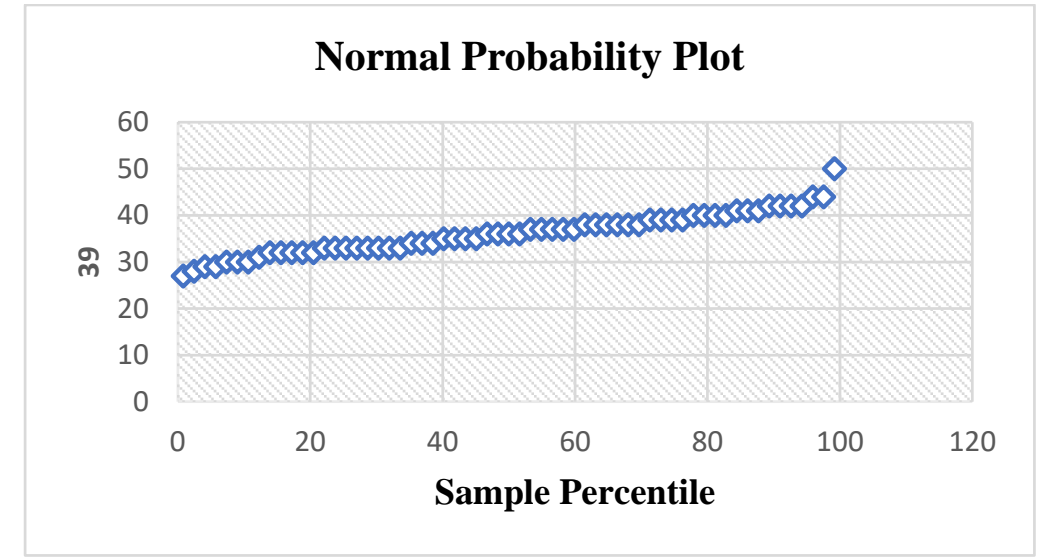

Gambar 1. Normalitas Probability Plot

Grafik probability plot pada gambar di atas memperlihatkan penyebaran data (titik-titik) disekitar garis regresi (diagonal) dan penyebaran titik-titik data searah mengikuti garis diagonal, maka dapat disimpulkan bahwa model regresi layak digunakan karena memenuhi asumsi normalitas.

\section{d. Pembahasan hasil penelitian}

Setelah melakukan penelitian dari hasil kuesioner, ternyata smartphone berpengaruh positif terhadap pemanfaatan akses e-jurnal oleh mahasiswa prodi Ilmu Perpustakaan Angkatan 2016-2017. Hal ini terlihat dari hasil penelitian yang menunjukkan bahwa smartphone mempunyai dorongan sebesar 31,8\% sementara sisanya $62,8 \%$ yang diterangkan oleh variabel lain yang tidak ada dalam penelitian ini. Presentase smartphone mempengaruhi dorongan mahasiswa untuk memanfaatkan akses jurnal elektronik sebesar 31,8\%.

Selanjutnya hasil analisis regresi linier sederhana diperoleh koefisien untuk variabel smartphone sebesar 0,602 dengan konstanta 17,303 sehingga model persamaan regresi linier sederhana yaitu : $\mathbf{Y}=\mathbf{1 7 , 3 0 3}+\mathbf{0 , 6 0 2 X}$. Berdasarkan hasil regresi linier di atas maka dapat di persentasikan bahwa setiap kenaikan variabel X (smartphone) $1 \%$ maka variabel Y (pemanfaatan akses $e$-jurnal) diperkirakan akan mengalami peningkatan sebesar $0,602 \%$.

Kemudian dengan kriteria keputusan Ho ditolak dan Ha diterima apabila thitung> tabel pada alpha 5\% sehingga hasil uji empiris pengaruh smartphone terhadap pemanfaatan akses $e$-jurnal di peroleh thitung sebesar 8,693 > dari tabel pada alpha 5\% sebesar 1,996. Jadi dapat disimpulkan bahwa thitung lebih besar dari tabel hal ini menunjukkan bahwa diterimanya $\mathrm{Ha}$ yang mengatakan adanya pengaruh positif dan signifikan antara smartphone terhadap pemanfaatan akses $e$-jurnal. 


\section{SIMPULAN}

Dari Hasil Pembahasan yang telah dilakukan dapat ditarik kesimpulan sebagai berikut :

1. Hasil analisis statistik menunjukkan data lapangan bahwa pemanfaatan smartphone guna akses elektronik (e-jurnal) oleh mahasiswa prodi Ilmu Perpustakaan Angkatan 2016-2017 memiliki nilai rata-rata sebesar 3,65yang dapat dikatagorikan tinggi karena berada di antara 3,42-4,23.

2. Hasil analisis statistik menunjukkan data lapangan bahwa pemanfaatan akses jurnal elektronik (e-jurnal) oleh mahasiswa prodi Ilmu Perpustakaan Angkatan 2016-2017 memiliki nilai sebesar 3,76yang dapat dikatagorikan tinggi karena berada di antara 3,42-4,23, dengan nilai tertinggi 4,12 yakni indikator mengakses jurnal elektronik untuk membantu dalam tugas perkuliahan .

3. Hasil pengujian Hipotesis menunjukan thitung lebih besar dari pada tabel hal ini menunjukan bahwa diterimanya Ha yang mengatakan adanya pengaruh positif dan signifikan antara smartphone terhadap pemanfaatan jurnal elektronik (e-jurnal) di oleh mahasiswa prodi Ilmu Perpustakaan Angkatan 2016-2017 Fakultas Adab dan Humaniora.

\section{DAFTAR PUSTAKA}

Hasan, M. I. (2002). Pokok-Pokok Materi Statistik 1 (Statistik Deskriptif). Jakarta: Bumi Aksara.

Indonesia. (2007). Undang-undang Perpustakaan No. 43 Tahun 2007. Jakarta: Perpustakaan Nasional RI.

Nikmah, A. (2016). Dampak Penggunaan Handphone Terhadap Prestasi Siswa. Dinas Pendidikan Kota Surabaya.

Oxford. (t.t.). Oxford English and Spanish Dictionary, Thesaurus, and Spanish to English Translator "Meaning of smartphone in English." Diambil dari https://www.lexico.com/definition/smartphone

Petersalim \& Yennisalim. (1999). Kamus Bahasa Indonesia Kontemporer. Jakarta: Modern English Press.

Rejeki, O. D. (2013). Pemanfaatan E-Journal yang dilanggan perpustakaan fakultas kedoktern Universitas Andalas Bagi mahasiswa kedokteran. Jurnal ilmu komunikasi informasi perpustakaan dan kearsipan.

Sugiyono. (2007). Metode Penelitian Kuantitatif, Kualitatif dan $R \& D$. Bandung: Alfabeta.

Sugiyono. (2015). Metode Penelitian Kuantitatif dan R\&D (Cetakan 11). Bandung: Alfabeta.

Wijaya, T. (2011). Cepat Menguasai SPSS 19 untuk olahan dan interprestasi data penelitian skripsi. Yogyakarta: Cahaya Atma Pustaka.

Zuriyah, N. (2009). Metode Penelitian Sosial dan Pendidikan Teori dan Aplikasi. Jakarta: Bumi Aksara. 